\section{Obesidade na Infância e Adolescência- Um Extraordinário Desafio!}

$\mathrm{C}^{\mathrm{s}}$ ERTAMENTE NÃO SEREI ORIGINAL AO AFIRMAR que a obesidade, em qualquer faixa etária, e particularmente na criança e no adolescente, constitui-se num formidável desafio para todos os profissionais envolvidos na busca de uma solução definitiva para o problema. Nos últimos anos, a verdadeira "explosão epidêmica" desta condição tem suscitado um notável interesse dos profissionais da área da saúde e a procura aos Congressos, aos Cursos, aos Simpósios e às publicações que tratam do assunto tem sido também verdadeiramente "epidêmica".

O tópico "obesidade" no Medline, no mês de agosto deste ano, levanta nada menos que 50.847 publicações. Quando se restringe a pesquisa aos adolescentes, 8.604 publicações e na criança, 11.999 artigos. Fica claro que, se conhecêssemos o problema em sua total extensão, se tivéssemos uma terapêutica uniformemente eficaz, não teríamos esta pletora de publicações.

A prevalência da obesidade tem aumentado progressivamente desde 1960 nos EUA, onde se contam com estatísticas mais confiáveis. Uma pesquisa realizada em 1991 (National Health and Nutrition Examination Survey - NHANES) mostrou que $22 \%$ da população americana adulta é obesa, definida por índice de massa corpórea (IMC) acima de $27,8 \mathrm{~kg} / \mathrm{m}^{2}$ para homens e $27,3 \mathrm{~kg} / \mathrm{m}^{2}$ para mulheres. A definição da Associação Americana de Cardiologia, que considera obeso quem tiver IMC maior do que 25 (ao invés dos atuais $30 \mathrm{~kg} / \mathrm{m}^{2}$ ), vai elevar ainda mais a prevalência de obesidade. Nos EUA, 15\% a 25\% das crianças adolescentes são obesas. Mais recentemente, os números têm aumentado, acreditando-se que $40 \%$ dos adultos americanos sejam obesos. Apesar de em outras partes do mundo, o problema da obesidade também ser importante, nos EUA o problema tem se mostrado mais grave que na Europa (1). Há dados referindo prevalência de obesidade em $1 / 3$ da população brasileira e as taxas não param de crescer e a desafiar as recomendações das organizações de saúde.

A etiologia da obesidade é nitidamente multifatorial e esse aumento de sua incidência nos últimos anos tem sido explicado pelos sociólogos e nutrólogos pelos fatores nutricionais inadequados (excessivo consumo de lanches, guloseimas, etc) associados a um excessivo sedentarismo (TV, vídeo-games, etc). No entanto, como ressalta Lustig (2), "atribuir este verdadeiro surto epidêmico de obesidade a fatores nutricionais e comportamentais é ignorar a biologia básica do equilíbrio energético. Claramente, a vontade de comer e de se exercitar tem uma base bioquímica e hormonal". A identificação de neurotransmissores controlados hormonalmente, que interferem no comportamento alimentar (neuropeptídeo Y, por exemplo), hormônios que regulam a lipogênese (insulina, por exemplo) e hormônios que sinalizam a adequação calórica (leptina) colocam em perspectiva uma nova compreensão dos mecanismos envolvidos nessa mudança de padrão corpóreo e talvez venham a permitir uma abordagem menos empírica e mais calcada em bases fisiopatológicas. Reconhece-se cada vez mais que a obesidade não é uma condição única mas um achado comum a várias situações patológicas.

\section{editorial}

\author{
Durval Damiani
}

Professor Livre-Docente, Unidade de Endocrinologia Pediátrica, Instituto da Criança - Hospital das Clínicas da Faculdade de Medicina da Universidade de São Paulo 
Vários genes têm sido relacionados à obesidade e a complexidade da regulação da ingestão alimentar não deve ser subestimada (recomendo aos leitores a excelente revisão de Kalra e cols [3]). Uma série de hormônios e neurotransmissores, bem como neuromoduladores de ação central estão envolvidos nesse processo. Neuropeptídeo $Y$, opióides endógenos (dinorfinas e $\beta$-endorfinas), orexígenos $\mathrm{A}$ e $\mathrm{B}$ e a galanina atuam aumentando a ingestão alimentar, enquanto colecistoquinina, CART (transcritos regulados por cocaína e anfetamina), dopamina, neurotensina e leptina, entre outros, atuam em sentido oposto. Estudos em que se provocam lesões hipotalâmicas e transecção cirúrgica de vias neuronais têm evidenciado o núcleo ventromedial, o núcleo dorsomedial, núcleos para-ventriculares e o hipotálamo lateral como os locais que controlam a sensação de fome e saciedade (3).

Nos últimos anos, a comunidade científica "redescobriu" o tecido adiposo, que passa da condição inercial, de mero depositário da gordura corpórea e com papel na proteção do indivíduo contra as baixas temperaturas ambientais, ao “... senão mais importante, pelo menos o mais versátil tecido endócrino já conhecido" (4). A leptina, inicialmente tida como a solução final para a obesidade, acaba não apresentando os efeitos esperados e, na imensa maioria dos obesos, seus níveis são elevados, implicando problemas de receptores, mais difíceis de serem resolvidos.

Um fato interessante que tem se repetido nas últimas décadas é que, a cada descoberta de algum fator envolvido na obesidade, alardeia-se a solução final do problema e isto tem mobilizado uma verdadeira multidão de pacientes obesos que saem à procura da "solução mágica" para o seu problema. Poucos estão realmente interessados em mudanças de hábitos mas a grande maioria quer "a fórmula", hoje sofisticada por programas de computador que combinam os mesmos produtos de formas variadas para alardear seus efeitos únicos. Pela quantidade de medicamentos destinados à perda de peso (anoréticos, sacietógenos, termogênicos, anti-depressivos, disabsortivos, etc) que se vende no mundo, deveríamos esperar que a raça humana, a esta altura do campeonato, fosse não somente magra, mas já desnutrida! Felizmente, temos grupos sérios realmente empenhados em resolver a grave questão da obesidade. Se o problema é complexo, não deve suscitar esmorecimento e a procura constante e séria de soluções deve ser a tarefa primeira de todos os envolvidos na sua terapêutica.

Na criança, o problema é ainda mais grave, já que uma criança obesa nos primeiros seis meses de vida tem 2,3 vezes mais probabilidade de se tornar um adulto obeso, enquanto que adolescentes obesos dos 10 aos 13 anos têm 6,5 vezes mais probabilidade de se tornarem adultos obesos. Então, fica muito claro o papel do Pediatra que deve, desde cedo, detectar seus pacientes que estão acima do peso e tentar modificar seus hábitos alimentares, freqüentemente sob o olhar alarmado dos familiares mais idosos (avós adoram netas e netos obesos, mas... até uma certa idade; eles imaginam que nós, médicos, dispomos de um interruptor que modifica a composição corpórea da criança no momento que quisermos!).

Uma conversa franca com os pais, geralmente faz com que eles percebam a importância do problema da obesidade. Quando a criança ou o adolescente começam a perder peso, fica muito claro que isto thes dá mais confiança para prosseguir e faz com que se sintam capazes de encarar uma tarefa que, reconheçamos, não é fácil. É como se quiséssemos manter nossa temperatura corpórea o tempo todo a $35^{\circ} \mathrm{C}$, quando nosso "set point" está regulado para $36,5^{\circ} \mathrm{C}$. Qualquer titubeio faz com que o paciente rapidamente volte ao seu peso anterior e, não raro, até a um peso superior ao anterior! Mecanismos homeostáticos estão presentes regulando a quantidade de tecido adiposo. $\mathrm{O}$ melhor conhecimento de tais mecanismos poderá permitir uma abordagem mais racional do paciente obeso. Apenas para se ter uma idéia dessa regulação, um adolescente ingere aproximadamente $800.000 \mathrm{kcal}$ por ano. Como cada $7.000 \mathrm{kcal}$ de balanço positivo representam um acúmulo de $1 \mathrm{~kg}$ de peso corporal, um erro nessa regulação homeostática de apenas $5 \%$ resultaria no ganho de $5,7 \mathrm{~kg}$ no decurso de um ano, o que, em situação normal, não ocorre. Portanto, cada um de nós tem seu "set point" particular para a regulação do peso. Ainda mais, as pessoas obesas necessitam de menos calorias que as magras para manter o mesmo peso, o que é consistente com a hipótese de que o metabolismo dos obesos é mais "eficiente" e o tecido adiposo é menos "perdulário" em relação ao consumo calórico.

Como bem frisado no artigo de Carneiro e cols (5), nesta edição dos "Arquivos", a obesidade tem sido vista por um percentual elevado de pacientes e familiares, não apenas como um problema estético, mas como um problema de saúde. $O$ estudo de 38 adolescentes obesos, comparados a 28 não obesos, deixa claro que as complicações da obesidade não precisam de muito tempo para se manifestar: hipertensão arterial, sinais clínicos de resistência a insulina (acanthosis nigricans), além de um perfil lipídico alterado, com redução de níveis de HDL-colesterol e elevação de triglicerídeos, já demonstram que o terreno para as futuras compli- 
cações está sendo preparado e requerem atuações no sentido de minimizá-las.

Temos observado em nossos adolescentes obesos uma aumentada resistência a insulina, evidenciada por uma relação insulina/glicose francamente alterada e a volta a padrões normais após perda de peso (curiosamente, mesmo antes de se atingir o peso ideal, a resistência a insulina já se reduz), o que mostra que devemos investir vigorosamente nesses pacientes, na tentativa de lhes propiciar um futuro mais saudável. $\mathrm{O}$ alerta que o trabalho de Carneiro e cols (5) deixa para todos os leitores tem grande papel nesta tomada de consciência por todos que lidam com crianças e adolescentes obesos: não achemos que o problema vá se resolver na vida adulta, como "fantasiosamente" muitos familiares (e alguns profissionais de saúde) dizem acreditar. Afinal de contas, a "solução mágica" é sempre mais fácil que a mudança de comportamento.

\section{REFERÊNCIAS}

1. Sanchez MB, Sarria-Chueca A. Obesidad. In: Tratado de Endocrinologia Pediátrica. $M$ Pombo Arias, ed. $2^{\mathrm{a}}$. edição. Diaz de Santos S.A. Ed., Juan Bravo, Madrid, 1997, pp:1157-70.

2. Lustig R. Childhood obesity. International Symposium on "A Current Review of Pediatric Endocrinology". April 2529, 1999; 133-9

3. Kalra SP, Dube MG, Pu S, Xu B, Horvath TL, Kalra PS. Interacting appetite-regulating pathways in the hypothalamic regulation of body, weight. Endocrine Rev 1999:20:68-100.

4. Kater CE. Obesidade: genética, fisiopatologia e terapêutica às vésperas de uma importante revolução conceitual (Editorial). Arq Bras Endocrinol Metab 2000:44/1:1-2

5. Carneiro JRI, Kushnir MC, Clemente ELS, Brandão MG, Gomes MB. Obesidade na adolescência: fator de risco para complicações clínico-metabólicas. Arq Bras Endocrinol Metab 2000;44/5: 390-6. 